\title{
ECONOMIA POLÍtTICA DO TERRITÓRIO E ESTRATÉGIAS DE ATRAÇÃO DE INVESTIMENTOS - A GEOGRAFIA DA SUBVENÇÃO INDUSTRIAL NO CEARÁ COMO EXEMPLO
}

\author{
Edilson Alves Pereira Júnior* \\ Eliseu Saveiro Sposito**
}

\begin{abstract}
Resumo: A tentativa de afirmar um projeto de industrialização pautado numa proposta política de integração irrestrita ao mercado foi um dos fatos mais marcantes a atingir o Ceará nas duas últimas décadas. O componente central que deve ser destacado na leitura dos acontecimentos é o papel decisivo das forças públicas na consolidação do processo. A participação dos governos estaduais não só se apresentou necessária como determinou os rumos da mudança, sobretudo ao proporcionar densidade técnica ao território e incentivar a mobilidade dos capitais através de programas políticos. Este artigo procura apresentar algumas reflexões acerca do tema, seguindo os caminhos da reestruturação espacial como instrumento da acumulação capitalista pela via da indústria. O conjunto articulado das ações e dos objetos formou a síntese estrutural de uma industrialização que logrou sucesso por combinar manifestações particulares e universais unificadas num plano concreto, o próprio território, que desde então não pode mais ser entendido sem que se considere a sinergia interescalar que o caracteriza.
\end{abstract}

Palavras-chave: Ceará, industrialização, economia política do território.

\section{TERRITORY ECONOMICAL POLITIC AND STRATEGIES OF INVESTMENT ATTRACTION - THE GEOGRAFY OF INDUSTRIAL INCENTIVES IN THE CEARÁ AS EXAMPLE}

\begin{abstract}
The attempt of assuring a modernization project guided by the purposes of unrestricted market integration and the globalization dynamics was one of the most relevant facts that hit Ceará in the last decades. The central component that must be singularized while analyzing the facts is the crucial role that public power played in consolidating the process. The participation of the state governments was not only necessary but also determined the paths of change, especially by providing technical density to the territory and encouraging capital mobility through laws and political programs. This paper seeks to present some reflections about this subject, following the paths of spatial restructuration as an instrument of capital accumulation by the industry. The articulated assemblage of actions and objects formed the structural synthesis of a type of industrialization that achieved success fundamentally by combining particular and universal manifestations unified in a concrete plan, the territory itself, that from then on cannot be understood without the multidimensional and multifunctional synergy that it characterizes.
\end{abstract}

Keywords: Ceará, industrialization, political economy of the territory.

\section{Introdução}

Este trabalho objetiva realizar um exercício de interpretação que correlacione indústria, território e políticas de atração de investimentos produtivos. As principais inquietações que nos motivam estão associadas às mais recentes combinações que se configuram com a reestruturação territorial e produtiva em tempos de mundialização da economia. O destaque é dado para a investigação da industrialização e seus rebatimentos sobre a organização espacial brasileira. Centramo-nos na análise da acumulação capitalista e a partir daí buscamos entender a fluidez adquirida pelos

\footnotetext{
* Professor do Departamento de Geociências da Universidade Estadual do Ceará (Uece). Doutor em Geografia pela Universidade Estadual Paulista (Unesp) Presidente Prudente. E-mail: edilsonapjr@hotmail.com.

** Professor titular do Departamento de Geografia da Universidade Estadual Paulista (Unesp) Presidente Prudente. E-mail: essposito@gmail.com.
} 
investimentos com a incorporação crescente de novas tramas produtivas, capazes de materializar o deslocamento de indústrias, sobretudo aquelas intensivas em mão de obra e que procuram multiplicar os lucros partir do aproveitamento de baixos salários.

Através da investigação do modelo de industrialização que se consolida no estado do Ceará desde os anos de 1990, tratamos os assuntos supracitados. Desse modo, enquanto presenciamos uma revolução tecnológica e produtiva nos países de maior tradição industrial e nas regiões mais ricas do Brasil, evidenciamos, em territórios como o Ceará, a transição de modestas relações de produção para relações capitalistas renovadas, cujo paradigma tecnológico e as formas de organização do trabalho parecem indicar um modelo mecanizado, no qual a flexibilização territorial e produtiva se instala ao lado da maximização da produção com base em ganhos obtidos por economias de escala, notadamente através de linhas de montagem definidas a partir de uma acentuada divisão do trabalho.

Como importante elemento constitutivo das transformações territoriais e econômicas, o Estado, representado pelo Governo do Ceará e por prefeituras locais, usa de incentivos fiscais e da modernização da infraestrutura para garantir a ampliação da atividade industrial e a inserção de grandes empresas de capital internacional e nacional no território, estimulando a migração de investimentos para cidades sem nenhuma tradição fabril.

Uma das prerrogativas dessa industrialização subsidiada é estimular o investimento industrial através de uma parceria com organismos internacionais, dos quais captam novas e diversificadas fontes de recursos. Desenha-se um conjunto de propostas que busca estruturar o território a partir de grandes obras técnicas, no intuito de garantir a dinamização da indústria de transformação.

Nesse sentido, o que se pretende no artigo é tentar aprofundar em que medida as características ora postas podem realmente confirmar uma reestruturação territorial produzida pela indústria associada às ações políticas e econômicas desenvolvidas no Ceará no contexto das transformações que resultam do atual processo de mundialização.

Objetiva-se, a partir daí, investigar em que medida tal projeto pode ter logrado sucesso e em quais pontos as propostas iniciais não foram atendidas. Busca-se também entender quais os gêneros industriais mais beneficiados com as políticas de atração industrial e como se configuram algumas formas espaciais específicas da industrialização, dentro de um contexto que priorize o caráter relacional entre as particularidades do território e o movimento do mundo.

Além dessa introdução, o texto reúne informações sobre a evolução econômica cearense, enfatiza questões relacionadas às políticas de desenvolvimento e de atração da indústria, elenca os gêneros industriais mais destacados, analisa a distribuição territorial dos objetos e dos fluxos dessa atividade econômica e descreve alguns resultados sentidos pelo Ceará como consequência da expansão da atividade industrial. 


\section{Evolução econômica no Ceará e a importância do estado para o desenvolvimento do processo de industrialização}

Para a compreensão do desenvolvimento econômico e industrial no Ceará, convém contextualizar a evolução da sua acumulação. Isto requer uma periodização da economia e da sociedade no contexto da indústria, essencial pois cada elemento do real muda de valor segundo o período histórico e, por isso, cada território está sempre mudando de significação. Como, a cada instante, as relações materializadas no território não são as mesmas, a apreensão destas especificidades é necessária (SANTOS, 2008). Assim, uma periodização em três momentos distintos será considerada.

O primeiro deles demarca uma fase em que o tripé gado/algodão/agricultura de subsistência demarcou a organização econômica e territorial no estado. $\mathrm{Na}$ verdade, a formação econômica cearense no "Brasil Colônia" se distanciou um pouco das outras economias nordestinas litorâneas. Enquanto os estados da Zona da Mata apresentavam suas economias baseadas na lavoura canavieira, o Ceará fundamentava sua organização econômica em função das necessidades de suprimento para as regiões agroexportadoras. Assim, a pecuária foi a primeira grande atividade produtiva, responsável pelo povoamento e à colonização do território.

Logo depois, somou-se à criação de gado e às charqueadas, as atividades produtoras de algodão. Este produto adaptou-se muito bem ao clima semiárido e, apesar de seu caráter agroexportador, veio dele o incentivo ao crescimento da indústria no Ceará, pois o seu excedente contribuiu decisivamente na criação de empresas de fiação e tecelagem (SILVA, 1994). Tais fábricas, que se distribuíram por diversos municípios, uniram-se a outras nos ramos de curtume, metalurgia, tipografia etc., formando a base industrial cearense que predominou até a década de 1960.

Em geral, nesse primeiro momento, a indústria se deu muito mais como um prolongamento da agricultura, tendo em vista que se centrou na transformação da matéria-prima local, se processou espontaneamente e destacou 0 investimento de grupos familiares radicados na província (AMORA, 1994).

O segundo momento deu-se a partir da inserção das práticas desenvolvidas pela Superintendência de Desenvolvimento para o Nordeste (Sudene), quando o Governo Federal propôs a implantação de projetos industriais dentro das estratégias centralizadas do planejamento regional. Os incentivos fiscais passaram então a ser aplicados tanto na "modernização e/ou ampliação de velhas atividades existentes [...], como também na instalação de novas indústrias" (AMORA, 1994, p. 127).

Nessa fase, consolidou-se o processo de industrialização no Ceará. Ocorreu um impulso econômico e industrial significativo e o Governo do Estado se mobilizou no intuito de aparelhar o território para um maior acesso aos incentivos regionais e aos investimentos externos. Inicialmente, houve um esforço no sentido de aperfeiçoar as condições de infraestrutura, no qual os destaques foram a montagem de uma rede de distribuição de energia elétrica, a ampliação e melhoria de estradas e uma maior eficiência nos dispositivos que iriam 
oferecer serviços de apoio técnico e financeiro ao setor. ${ }^{1}$

A ação das forças públicas se mostrou então imprescindível no que diz respeito à montagem e consolidação de novas relações capitalistas no Ceará. O processo gradativamente evidenciou a materialização dos novos investimentos industriais e no fim da década de 1970 a economia cearense reestruturou 0 seu sistema produtivo, notadamente ao trocar a proeminência econômica centrada no modelo agrário exportador por outra mais fortemente influenciada pela indústria e as atividades urbanas.

Tal mudança, que vinha acompanhada no plano político por uma série de reformas, foi confirmada através do uso de medidas emblemáticas de incentivo à industrialização. Com o apoio do Governo Federal e pretendendo criar um III Polo Industrial para o Nordeste, ao acompanhar a expansão sentida por Bahia e Pernambuco, o Governo do Estado, em 1979, lançou o II Plameg (II Plano de Metas Governamentais), e intensificou as ações na atividade industrial. O I Plameg, idealizado em 1963, já havia imprimido no governo estadual uma visão de planejamento estimulada pelas ações da Sudene. Tinha priorizado aparelhar o estado de infraestrutura básica para materializar uma empreitada industrializante. O II Plameg propunha dar continuidade ao projeto inicial.

Mas as alterações do período não implicaram uma mudança da estrutura industrial cearense. Como informa Amora

1 Criaram no período a Superintendência de Desenvolvimento do Ceará (Sudec), a Companhia de Desenvolvimento do Ceará (Codec), o Banco do Estado do Ceará (BEC) e o Banco de Desenvolvimento do Ceará (Bandece).
(1994, p. 127), "manteve-se a estrutura industrial existente antes da política de incentivos fiscais, com o predomínio das atividades consideradas tradicionais, aquelas que utilizavam matérias-primas locais". Situação semelhante ocorreu com a distribuição espacial das riquezas industriais, pois a maioria dos investimentos se cristalizou no ambiente mais propício à sua reprodução, a cidade de Fortaleza.

As mudanças engendradas no período, entretanto, influenciaram decisivamente a política e a economia no Ceará e, por consequência, sua evolução industrial. A tentativa de afirmar um projeto de modernização pautado numa proposta de integração irrestrita ao mercado e à dinâmica da mundialização foi um dos resultados mais marcantes da transformação supracitada. Como resultado das alterações proporcionadas pela Sudene e pelo Fundo de Investimentos do Nordeste (Finor), ${ }^{2}$ deu-se o aparecimento de uma classe burguesa bem sucedida que, pelas suas origens urbanas, diferenciou-se, a um só tempo, das elites políticas tradicionais e da classe empresarial mais antiga, ligada a estrutura econômica do Estado autoritário.

Essa classe empresarial sentiu a necessidade de levar a frente uma proposta racionalista de intervenção planejada na economia e na política e passou a discutir abertamente tais temas, conquistando o poder estadual no Ceará em 1986. Reestruturar o território e construir uma

\footnotetext{
${ }^{2}$ O Finor foi um mecanismo fiscal criado na década de 1970 que liberou o financiamento para pessoas jurídicas interessadas em investir em projetos de médio e grande porte no Nordeste. Tal mecanismo atendeu ao empresariado cearense que possuía fábricas de gêneros tradicionais como o têxtil e o de alimentos, e a indústria estadual cresceu sobremaneira a partir de sua atuação.
} 
imagem positiva do seu papel na transformação da sociedade seria uma prioridade da nova política, o que oportunizaria a fluidez dos movimentos e a interconexão entre os lugares, essenciais para que um conjunto de mudanças econômicas pudesse ser firmado em sintonia com as demandas da mundialização.

Projetou-se um redesenho do território, que passou a ser esquadrinhado e reestruturado a partir do soerguimento de inúmeros objetos técnicos, e uma política de benefícios tributários foi montada para garantir a "alavancagem" de investimentos que pudessem materializar o plano de transformação industrial. Essas intervenções, reproduzidas por todas as gestões do governo estadual até o presente momento, somaram-se às demais vicissitudes do território e constituíram vantagens competitivas geradoras de efeitos de encadeamento capazes de atrair capitais diversos.

A partir daí a evolução industrial cearense entrou num terceiro momento. Assumiu um perfil de crescimento no estilo do projeto de modernização implementado por esses "empresários-políticos". Assim, com a máquina pública reajustada, algumas propostas de intervenção estatal começaram a ser encaminhadas. Como esse é um momento de retração do papel do Governo Federal na promoção direta dos investimentos nacionais, a mobilização por recursos, financiamentos e empréstimos deuse a partir da entrada de novos agentes nacionais e internacionais no contexto.

A subordinação da política aos interesses de mercado buscou a expansão dos negócios privados no estado e o modelo de gestão empresarial da coisa pública contou, desde o primeiro momento, com a presença de técnicos e empresários no comando das principais secretarias de governo, garantindo o estabelecimento de redes externas que vinculassem o setor estatal ao privado. 0 "consenso tecnocrático", pautado num ideário de ajuste fiscal público e de "alavancagem" de investimentos, convergiu com as sugestões do "Consenso de Washington", segundo o qual a gestão pública deveria administrar uma "máquina" menor, flexível e eficiente, que deveria aprofundar o relacionamento com as instituições financeiras internacionais, diversificando e ampliando as fontes de financiamento dos programas de desenvolvimento.

Assim, uma das prerrogativas dessa nova fase da industrialização cearense, agora muito mais marcada por novas relações interescalares, seria estimular o investimento industrial através de uma parceria com organismos internacionais dos quais captariam novas e diversificadas fontes de recursos. O mercado financeiro internacional começou a influenciar mais diretamente a reestruturação territorial, especialmente através de agências de financiamento e bancos como o Banco Interamericano de Desenvolvimento (BID), o Banco Mundial, o KFW e o DEG (Alemanha) e o Banco de Desenvolvimento do Japão, entre outros (CEARÁ, 1991; 2006).

No âmbito industrial, as metas mais importantes propunham o incentivo às micro e pequenas empresas, a construção de minidistritos industriais no interior do estado, a atração de grandes investimentos a partir de isenção fiscal e a montagem de uma infraestrutura aeroportuária para garantir a 
instalação definitiva de uma siderúrgica de grande porte e de uma refinaria de petróleo.

Apesar das amplas possibilidades abertas para o incentivo à indústria de base e aos pequenos produtores do interior do estado, a continuidade das políticas de atração industrial assumiu definitivamente um corte conservador e centrou-se no financiamento público de indústrias externas, com o Governo Estadual priorizando políticas de atração indiscriminada de investimentos, oferecendo benefícios fiscais e garantias de lucratividade para qualquer capital interessado em deslocar suas unidades de produção para o território cearense.

O resultado mais contundente do modelo industrial desenhado pelos governos estaduais, foi a flexibilização das ações estatais em sintonia com um planejamento compartilhado com o setor privado de fora do Ceará. O impacto da chegada de novos investimentos externos foi expressivo e a partir de 1995 uma entrada galopante de empresas registrou-se no território cearense, notadamente aquelas de mão de obra intensiva, com predominância dos gêneros de calçados, alimentos e bebidas e vestuários.

Do projeto industrial proposto inicialmente, apenas a atração do grande capital foi lograda, enquanto a ideia de garantir maior dinamização produtiva ao interior através do patrocínio a pequenos empreendedores não obteve sucesso. Também foi frustrante a tentativa de legitimar a instalação de uma siderúrgica e de uma refinaria, o que implicou em novas propostas de reestruturação territorial, agora ligadas à montagem de um sistema de fixos localizado numa área que seria incluída na
Região Metropolitana de Fortaleza, o Complexo Industrial e Portuário do Pecém.

A concretização do modelo industrial supracitado se deu, notadamente, em função da simetria entre os interesses do território e os interesses dos agentes hegemônicos que demarcam a configuração capitalista de acumulação em tempos de mundialização da economia (CHESNAIS, 2006; SANTOS, 1999). A industrialização cearense se configura muito mais em função da síntese interescalar que reúnem as intencionalidades de forças territoriais endógenas e exógenas. Em nome da emergência da competitividade como força reguladora da concorrência dos mercados produtivos internacionais, novas estratégias espaciais são adotadas e muitas empresas buscam a regulação ideal das taxas de lucro transferindo unidades de produção para onde as medidas de contenção de gastos possam ser instaladas com maior facilidade. A desregulamentação dos mercados e do processo produtivo em favor de agentes hegemônicos globais chega ao Ceará, não sem antes atender as demandas das empresas por mão de obra barata e benefícios fiscais.

\section{Estrutura industrial e organização do território}

Como já apontado, apesar da programática governamental no estado do Ceará ter definido um projeto de industrialização ancorado em três eixos estruturantes, quais sejam: (1) a criação e/ou aparelhamento de arranjos produtivos locais; (2) a montagem de um complexo petroquímico/siderúrgico e (3) a atração de unidades produtivas industriais dos mais diversos gêneros; somente este último 
materializou componentes que de fato representou uma transformação efetiva da organização espacial da indústria.

Configurou-se um processo de industrialização que pretendeu afirmar uma transformação burguesa eficiente, capaz de unir acumulação ampliada no território com oferta irrestrita de benefícios fiscais a agentes capitalistas exógenos. Entretanto, o modelo não realizou nada mais do que a inserção do Ceará, enquanto um "lugar de reserva" (SANTOS, 1999), nos circuitos espaciais da produção de importantes empresas nacionais e estrangeiras, tecendo complexos círculos de cooperação viabilizadores de uma projeção imagética, política e econômica das elites dirigentes estaduais.

O fato é que, às ofertas de incentivos fiscais, somaram-se uma força de trabalho a baixo custo e uma localização privilegiada em relação ao mercado internacional para atrair investimentos pouco interessados em tecer aproximações com o lugar.

Por sua vez, na sincronia com o mundo, foi articulada a demanda da política com a capacidade adquirida pelos capitais produtivos de acelerar os movimentos por meio de novas tecnologias de informação. Isso fez da relação global/local um sistema integrado em rede que serve aos interesses hegemônicos de acumulação ampliada em curto prazo.

Na perspectiva do Ceará, estão presentes diversos tipos de agentes investidores e variadas escalas dessa configuração que elege o território como mecanismo de exploração. Identificamos:

(1) O grande capital produtivo, que escolheu a via da mundialização para coordenar mais intensamente suas atividades de geração de excedente, a exemplo de conglomerados internacionais como a Nike ou a Danone. São empresas que ora estabelecem acordos prolongados com outras firmas subcontratadas para atender demandas de produção, ora investem diretamente no processo produtivo, aproveitando as vantagens que o território cearense tem para oferecer. Para ficarmos nos dois exemplos citados, a Nike tem contrato com pelo menos três empresas nacionais que fabricam calçados sintéticos no interior do Ceará; e a Danone instalou em Maracanaú, na Região Metropolitana de Fortaleza, uma grande fábrica na qual investe expressivo volume de capital.

(2) Os investidores financeiros que, no estado, fazem-se presentes garantindo empréstimos diretamente ao governo ou às empresas industriais privadas, cobrando altas taxas de juros e impondo metas de rendimento que estão proporcionalmente relacionadas aos níveis de produtividade e lucratividade registrados na indústria, o que não é possível sem taxas elevadas de exploração da força de trabalho. Devemos aqui considerar a maior liberalização permitida aos fluxos financeiros internacionais por meio do tripé desregulamentação/desintermediação/ descompartimentalização (BOURGUINAT, 1992). Ela permitiu às empresas cearenses captarem importante volume de recursos por meio de "empréstimos intercompany", em que, ao invés de aporte de capital, o investidor estrangeiro entra com um empréstimo para a empresa local. No Ceará, tais operações estão presentes, sobretudo, na grande indústria têxtil e na indústria de alimentos, constituídas por capitais locais e que dominam o mercado nacional nos últimos anos. Segundo reportagens do jornal O Povo, 
publicada em 31 de maio de 2008, ao todo, são mais de duas mil participações do capital estrangeiro na economia cearense, seja como investimento direto externo, seja como empréstimo financeiro, o que totaliza uma quantidade superior a um bilhão em recursos atraídos.

(3) Os grandes produtores nacionais de bens de consumo, notadamente a indústria intensiva em mão de obra, que a partir da década de 1990, em função da abertura dos mercados no Brasil, deparou com a concorrência capitalista internacional e orquestrou um movimento de relocalização das suas unidades produtivas a fim de reduzir custos e manter-se "competitiva". As indústrias de calçados, de alimentos, têxteis e de vestuários, entre outras, estão entre as que mais utilizaram essa estratégia. Elas negociam vantagens competitivas com os governos cearenses e instalam plantas de grande porte na Região Metropolitana de Fortaleza e no interior do estado, aproveitando um conjunto de virtualidades que o território pode oferecer.

(4) Os investidores nacionais que não necessariamente representam grandes grupos econômicos ou estão vinculados a corporações globais. Eles agem em função das estratégias de externalização dos riscos produtivos engendradas por empresas maiores ou são atraídos pela demanda da grande indústria por insumos e componentes, sem os quais a realização do processo produtivo não poderia se efetivar. Estão incluídos neste rol grandes e médias empresas do Ceará ou de outros estados que complementam a atividade industrial ou realizam a própria produção através de redes de subcontratação.

Além de atender a programática de atração de investimentos projetada pelos governos do Ceará, as formas concretas de organização industrial descritas respeitam o imperativo que reproduz os sistemas territoriais do nouveau monde industriel (VELTZ, 2008). Eles são caracterizados por uma tessitura renovada que integra uma rede de relações estabelecidas em múltiplas escalas, geradora de fluxos materiais e imateriais diversos.

As interações espaciais e a divisão interempresarial do trabalho tornam-se mais complexas e a fabricação na indústria cearense tende a envolver diferentes empresas industriais e de serviços, materializando relações produtivas, financeiras e comerciais através da articulação de agentes em várias partes do mundo. É desse modo que se completa a ampla combinação de atividades como operações financeiras, gerências administrativas, estratégias de marketing, designer industrial, serviços de transporte e comunicação e a produção propriamente dita, seja de componentes específicos ou do produto acabado.

No território do Ceará, em função das características anteriormente apontadas, centram-se principalmente as atividades produtivas de bens de consumo, isto é, a produção industrial de gêneros intensivos em mão de obra. Muitos destes gêneros têm tradição na indústria cearense em função dos investimentos realizados por capitais locais. No entanto, os capitais atraídos demarcam um novo rumo para o processo produtivo, pois, além da nova composição multi e interescalar, produzem mais e voltam-se, muitas vezes, para o mercado internacional, estimulando a produção racionalizada no chão da fábrica e a maior geração de empregos formais. 
No caso dos investimentos contemplados com os incentivos fiscais, é explícito que a categoria mais beneficiada com a atração de estabelecimentos, investimentos e geração de empregos é a de trabalho intensivo, confirmando a hipótese segundo a qual a indústria tradicional foi a mais beneficiada com as políticas de incentivos fiscais. Segundo a Agência de Desenvolvimento do Ceará (Adece), ela reúne $55,7 \%$ das unidades instaladas, $44,8 \%$ dos recursos investidos e $77,3 \%$ dos empregos iniciais previstos de 1995 até 2009.

Isso demonstra que o deslocamento de empresas de outros estados para o Ceará está sujeito a dois movimentos principais. O primeiro deles é a própria organização da estrutura econômica, das normas e dos objetos técnicos no território, ainda incapaz de proporcionar atração de investimentos em indústria de bens de capital ou de alta tecnologia, revelando o caráter periférico e tardio da industrialização em curso.

O segundo está relacionado às demandas das empresas interessadas em migrar do seu local de origem. A partir de um conjunto de cobranças determinado pelas novas configurações de acumulação capitalista, as indústrias costumam ceder à força das concorrentes, sendo anexadas por elas, ou abrem-se definitivamente para a guerra econômica sem quartel (PETRELLA, 1996), e se utilizam de estratégias renovadas de reestruturação produtiva e territorial, no intuito de aproveitarem as vantagens da diferenciação espacial.

No âmbito da organização espacial da indústria no interior do estado, todos os documentos que embasam as políticas de apoio à instalação industrial demonstram intencionalidade em romper com o modelo de concentração produtiva nas áreas mais dinâmicas, que, no caso do Ceará, corresponde à Região Metropolitana de Fortaleza e às regiões do Cariri e Norte do estado, esta última representada pela cidade de Sobral e sua área de influência direta.

O histórico da produção espacial cearense, entretanto, registra que poucas são as áreas industriais consolidadas, isto é, aquelas verdadeiramente estruturadas pela atividade fabril. Estamos considerando, obviamente, os espaços industriais que resultam da maximização da produção com base em ganhos obtidos por economias de escala, demarcados pela localização de empresas pequenas, médias ou grandes, caracterizadas, notadamente, por linhas de montagem definidas a partir de uma divisão do trabalho. Podemos adotar, com Fischer (2008, p. 53), o termo zona industrial, que pode resultar de uma intervenção do Estado ou da aglomeração de estabelecimentos produtivos em áreas urbanas adensadas, mas não deixa de se constituir como um "espaço específico ligado a uma infraestrutura específica", na qual é desenvolvida a atividade da indústria.

Essas concentrações de atividades produtivas estão relacionadas à capacidade local de dinamizar a economia e criar novos sistemas espaciais onde a indústria inicialmente pouco contribui para a geração de excedente, todavia logo abandona a sua posição residual e assume o controle dos processos de acumulação, acarretando grandes modificações no espaço e no conteúdo das cidades. No Ceará, entretanto, apesar da proeminência que a indústria ganhou ao longo do século $X X$, outras atividades exerceram historicamente mais 
impactos sobre as potencialidades econômicas e políticas.

Como a formação do território está vinculada principalmente ao desenvolvimento de atividades ligadas à pecuária e ao plantio do algodão para o mercado externo, os núcleos urbanos melhores servidos de vias terrestres tinham suas praças comerciais mais desenvolvidas, melhor distribuindo também os bens e serviços para áreas vizinhas (SOUZA, 2005). A expansão desse modelo de organização espacial numa área dominada pelo clima semiárido deu à urbanização cearense uma estrutura marcada pelas desigualdades políticas e de oportunidades, na qual poucos centros urbanos diversificaram seus serviços e ampliaram sua área de influência. Mesmo quando o faziam, voltava-se para o desenvolvimento de atividades comerciais, tornando a indústria menos importante para o condicionamento dos processos econômicos.

Assim, a indústria teve menor influência na evolução da organização espacial e na projeção dos centros urbanos no Ceará. De igual maneira, quando se desenvolveu, ela o fez subordinada à expansão urbana e comercial de centros como Fortaleza, Sobral e Juazeiro do Norte, que reafirmaram sua força econômica ao diversificar atividades produtivas e fortalecer sua infraestrutura fabril.

É dentro desse contexto que a dinâmica econômica proporcionada pela nova fase de industrialização subsidiada no Ceará procurou redefinir a organização espacial da indústria no estado. A política de atração de investimentos considerou as margens de concentração industrial metropolitana e ofereceu maiores incentivos e facilidades para os empreendimentos interessados em se instalarem fora da área de influência direta da metrópole. Reiteradas vezes as políticas industriais concederam subsídios mais significativos para uma empreitada dessa natureza, traduzidos em melhor financiamento do ICMS ou em maiores garantias de montagem da infraestrutura da planta industrial, além de benefícios cedidos para as empresas que procurassem exportar o produto fabricado.

Seria muito mais vantajoso para o empresariado industrial instalar novos investimentos fora da área de influência da metrópole, principalmente se considerarmos que a maioria das firmas interessadas na relocalização produtiva buscava, de fato, ganhos de competitividade associada à isenção tributária e à exploração da força de trabalho, negociando sua produção para os mercados externos. Mesmo assim, se o objetivo era garantir desconcentração industrial a partir das vantagens supracitadas, o mecanismo foi pouco eficiente, como demonstra o Cartograma 1.

Apesar de alguma difusão dos investimentos industriais pelo interior, a maior densidade de estabelecimentos subvencionados dá-se nitidamente na Região Metropolitana de Fortaleza, com certa concentração também na região do Cariri e em Sobral. Se usarmos uma metodologia que definam zonas de ocupação e densidade no território dividindo-o em quatro partes, como fizeram as políticas de subvenção industrial no estado, confirma-se a organização espacial descrita.

Na primeira zona, que corresponde ao anel metropolitano, todos os municípios 
foram contemplados com pelo menos uma instalação e a capacidade de aglomeração das zonas industriais de Maracanaú, Fortaleza, Horizonte-Pacajus e Caucaia é explícita. A preferência pelo ambiente metropolitano confirma que deslocar unidades produtivas para regiões sem nenhuma tradição industrial tem seus limites e que os fatores de localização da produção ainda respeitam alguns princípios de aglomeração, acessibilidade e interação espacial. Assim, mesmo que a maioria dos empreendimentos subvencionados tenha sido de indústrias tradicionais, a decisão pela centralidade no âmbito do território se faz prevalecer.

Cartograma 1 - Municípios beneficiados com unidades produtivas industriais atraídas pelos incentivos dos governos do Ceará

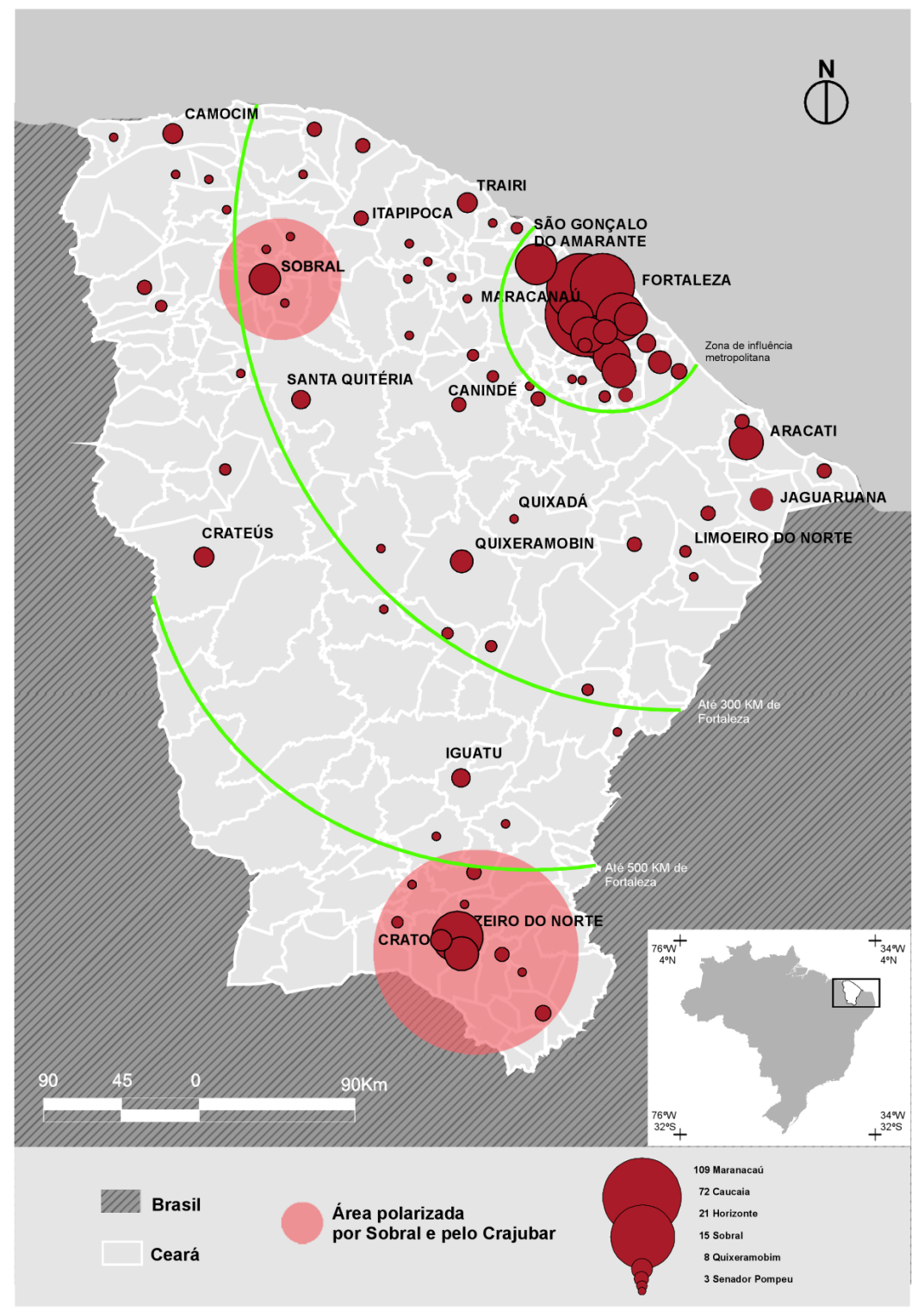

Fonte: Agência de Desenvolvimento do Ceará (Adece, 2010). Elaboração dos autores, 2011.

Numa segunda zona, demarcada por um raio que abrange 300 quilômetros de distância a partir da capital, a densidade de estabelecimentos diminui. Nesse trecho, um bom número de municípios (37) é contemplado com a chegada de empreendimentos. No entanto, são poucas as unidades produtivas ali instaladas, e os 
municípios que mais concentram investimentos, tais como Aracati e Trairi, desenvolvem, na verdade, atividades ligadas ao criatório de camarão ou à geração de energia elétrica por fontes eólicas, isto é, atraem capitais que não são materializados em fábricas industriais.

As condições concretas que permitem a atração de capitais externos nesta zona são materializadas nos municípios de Sobral, Quixeramobim, Santa Quitéria, Canindé, Quixadá e Itapipoca. Eles são contemplados com empresas novas e sentem a realidade econômica local fortemente alterada em função do aporte de recursos. Ao dar mais atenção aos empreendimentos ali instalados, é possível perceber que o gênero de calçados reúne praticamente todas as fábricas montadas. Como a estratégia dos capitais investidos no segmento calçadista diferenciase da dos demais setores da produção industrial no estado, podemos afirmar que o exemplo citado foge um pouco do padrão espacial assumido pela indústria subvencionada no Ceará. A indústria calçadista age de maneira mais desconcentrada, selecionando lugares que garantam altas margens de lucratividade a partir da exploração da força de trabalho e este comportamento contribui para que esta segunda zona possa ser melhor atendida por novos investimentos industriais. Todavia, a inserção dos municípios citados nos ritmos da indústria moderna é dada pela precarização do emprego e isto legitima o sentido da desigualdade socioeconômica cada vez mais presente no sertão cearense.

Esse movimento está longe de atender os interesses de uma política de industrialização distributiva, capaz de proporcionar interiorização do desenvolvimento, mas revela-se eficiente na estratégia de introduzir novas relações de produção e trabalho em áreas distantes, confirmando como certas formas de acumulação na indústria, quando vinculadas aos valores da mundialização competitiva, podem usar o território e o seu arranjo descontínuo como ferramenta para atender novas metas de lucratividade.

Finalmente, temos a terceira e a quarta zona de instalação de estabelecimentos, onde praticamente não há alteração nas formas mais antigas de distribuição da indústria. A paisagem da caatinga não é aqui alterada em nome da implantação de fábricas industriais e a monotonia dos espaços agrícolas do sertão só é interrompida com a presença de poucas unidades produtivas nos maiores centros urbanos, notadamente nas cidades de Iguatu, Crateús, Tianguá, Camocim e nos núcleos mais importantes da região do Cariri.

Nessas duas últimas zonas, uma ênfase deve ser dada à região do Cariri, principalmente o recorte conhecido como Crajubar (Crato, Juazeiro do Norte e Barbalha). Ele integra a expansão dos investimentos regionais com a chegada de capitais externos, sobretudo nos gêneros calçadista, metal-mecânico, químico e de confecções. Juazeiro do Norte é, sem dúvida, o município que melhor expressa o fenômeno descrito. Além de uma maior quantidade de empresas fabricantes de joias, peças de vestuário, refrigerantes, móveis e produtos de couro, é no seu território que se desenvolve um sistema industrial localizado de calçados, a reunir empresas dos mais diversos tamanhos. Todas estas fábricas ganham a companhia de empresas externas do segmento metal-mecânico, como a Singer 
do Brasil LTDA., ou de fabricantes de produtos químicos e de componentes de calçados, como a Lico Tintas Industriais LTDA. Juntas, dinamizam uma produção industrial que resulta da diversificação econômica caririense, mas que é ampliada a partir do reforço de empresas atraídas por subsídios fiscais do governo.

É possível constatar, nesse sentido, que a nova industrialização cearense acirra as desigualdades espaciais do quadro produtivo. A despeito do vazio industrial em vastas áreas, a concentração de investimento em certas regiões no Ceará é explícita. Essa é uma característica espacial do processo de industrialização, mas quando se manifesta no território cearense, onde as desigualdades socioeconômicas são significativas, a tendência ao acirramento da concentração de renda em regiões economicamente mais estruturadas é evidente. O espaço industrial do estado fica demarcado pelo soerguimento de objetos modernos e por uma eficiência das infraestruturas em centros de maior destaque, mas a negligência para com as áreas menos favorecidas permanece, conservando a pobreza do semiárido e ampliando a transferência de riquezas e de habitantes das regiões mais pobres para as regiões mais ricas.

O território, então, sente muito mais profundamente os efeitos de uma política tecnocrática fundamentada nos preceitos de uma economia aberta de mercado. De um lado, se materializam espaços de prosperidade e de avanço econômico, a destacar zonas de centralidade empresarial e urbana; e de outro, malgrado aos avanços sofridos pela economia, cria-se uma significativa pressão migratória responsável por transformações importantes, destacadas, entre outros, pelo aumento da capacidade de os centros urbanos estruturados atraírem e concentrarem uma população de baixa renda.

\section{Considerações finais}

Os governos que estimularam 0 projeto de atração de capitais produtivos no Ceará a partir da década de 1990 aproveitaram o momento decisivo de renovação política nacional e estadual para efetivar um crescimento industrial que logrou sucesso fundamentalmente em razão de uma sintonia interescalar e multidimensional. Ao ter o Leste Asiático como modelo para o processo de desenvolvimento econômico, configurou-se uma industrialização que não contemplou os encadeamentos entre setores e capitais de diferentes tamanhos, adotando, na verdade, um projeto de acumulação industrial pautado na atração de investimentos externos que teve nas isenções fiscais e na reestruturação do território condicionantes estratégicos de dinamização produtiva.

Às ações normativas empreendedoras, somou-se o minucioso redesenho técnico do território, materializado através de inúmeros objetos modernos que facilitaram a interconexão entre os lugares. Somente assim, a eficiente gerência da flexibilização industrial pôde ser realizada, tornando a fragmentação produtiva uma realidade e a complementaridade do circuito produção/circulação/distribuição/consumo no Ceará um dado concreto.

A instrumentalização do espaço destaca o Ceará como um território que se articula ao movimento das forças hegemônicas da mundialização. Ele foi 
esquadrinhado, entrecortado e realinhado em função de relações econômicas e políticas que tiveram um amparo local na sintonia com o movimento do mundo, engendrado por um sistema de técnicas que organiza a materialidade e está a serviço de alguns interesses.

Da mesma forma, as políticas interessadas na atração de investimentos pela via de subsídios fiscais empreenderam relevantes transformações no quadro produtivo industrial cearense, embora seus efeitos no território tenham sido o acirramento dos quadros de desigualdade e o reforço econômico de regiões historicamente já estruturadas.

Assim, mesmo com a preocupação de garantir dinamismo econômico para vastas áreas do sertão, o modelo de desenvolvimento seguido nestes últimos anos não concretizou uma desconcentração industrial e produtiva capaz de dinamizar o quadro econômico ou de modificar o quadro de pobreza de isolados municípios do interior do Ceará. Na verdade, a partir da proposta seguida, fortalecem-se as desigualdades e isso torna a metrópole e sua região de entorno, subsidiariamente os centros regionais de Juazeiro do Norte e Sobral, os ambientes mais propícios à intensificação dos ritmos industriais e econômicos.

Acreditamos que, no contexto das políticas industriais implantadas, um dos fatores que culmina com a organização espacial desigual é pensar o território como um produto neutro, influenciado por uma atmosfera onde impera o perfeito equilíbrio de mercado. Insiste-se na leitura de um território isotrópico (plano e homogêneo), condicionado a partir de interesses individuais de maximização dos lucros, onde é sempre o empresário o maior responsável pela última decisão de instalação de um estabelecimento.

$\mathrm{Na}$ verdade, sabemos que, face às demandas de alocação ótima de um investimento, muitos componentes precisam ser analisados, em especial o papel dos agentes concretos e dos processos estruturantes, sempre observados num contexto interescalar. Pensar o território somente como um invólucro, numa contextura socioespacial apolítica, é completamente discrepante para com a organização da indústria no Brasil e no mundo, principalmente quando se trata da região Nordeste e do novo modelo de industrialização cearense.

É justamente a reestruturação do território articulada aos movimentos que integram forças econômicas e políticas no âmbito da mundialização que materializam os novos componentes da ordem industrial. Como a tendência das políticas citadas é a de negligenciar a influência de componentes subjetivos e as contradições socioespaciais, o resultado de um programa industrial com modelos preconcebidos, como salienta Fischer (1994), é a produção de uma leitura da localização produtiva como um conjunto de catalogues-répertoires, ao estilo do princípio básico que orienta o Cartograma 1, isto é, um padrão idealizado de ação locacional em que a instalação da indústria deve ser orientada com base em círculos concêntricos que partem de um polo com forte poder de centralidade. ${ }^{3}$

\footnotetext{
${ }^{3}$ Muitos modelos tradicionais de interpretação da localização industrial foram produzidos usando esquemas de crescimento estáticos refletindo circuitos econômicos rígidos e estacionários. Como
} 
A industrialização do Ceará evidencia que as motivações reais que induzem ao processo de acumulação de capital, assim como as decisões sobre o ambiente ideal de alocação dos investimentos, muitas vezes escondem-se sob formulações políticas, sendo estas apresentadas como objetivos sociais a fim de obter efeitos em nível ideológico. É preciso enfatizar o quanto essa discussão passa pela análise da desigualdade territorial e das políticas de desenvolvimento capitalista, o que concede à dinamização da atividade industrial um caráter de discussão político-governamental.

A concepção que enfatiza o papel dos governos e das forças econômicas e políticas, a movimentarem as relações sociais de produção, esclarece muito melhor o processo. Dentro desse contexto, o território deve ser lido como uma instância condicionante e condicionada, um produto concreto de manipulações que podem ser realizadas a partir de inúmeras intencionalidades.

afirmam Aydalot (1980) e Manzagol (1985), tais modelos prenderam-se a uma abordagem que buscava a aplicação pura e simples de mecanismos de ajustamento do equilíbrio com base num sistema econômico de livre mercado, o que torna seu poder de análise hoje superado. No caso específico dos círculos concêntricos, sua formulação está associada, entre outros, ao princípio da produtividade marginal de Von Thünen, para o qual os preços de mercado aumentam segundo a distância dos locais de produção ao mercado central (AYDALOT, 1980; MANZAGOL, 1985; MÉNDEZ; CARAVACA， 1996; CAMAGNI, 2005).
Definir a interpretação do processo nos termos descritos ajuda na leitura dos interesses ideológicos e no reconhecimento dos agentes voltados para a defesa de certas causas, geradoras de desigualdades. Revelar tais conjunturas implica em produzir a crítica na perspectiva de pensarmos na definição de outro modelo; um modelo que possa ser visto como um meio para auxiliarem certas coletividades locais, reforçando o potencial econômico e as funções centrais de cada região ou lugar.

Isso pode funcionar como um meio de orientação que supere as segregações ora postas, sobretudo ao permitir que o espaço seja reconhecido como moradia do homem (SANTOS, 2004), um produto da convivência humana e das relações sociais estabelecidas pelos que nele vivem e trabalham. Desse modo, o território, que hoje é visto como oportunidade de acumulação ampliada de riquezas por agentes dominantes, poderá se destacar pela sua capacidade de produzir novos horizontes criados a partir de uma convivência solidária, nascida das relações culturais, sociais e políticas de cada coletividade, a permitirem a construção de diferentes modalidades de desenvolvimento industrial que tornem o espaço passível de uma ampla apropriação por parte da sociedade.

\section{Referências bibliográficas}

AGÊNCIA DE DESENVOLVIMENTO ECONÔMICO DO CEARÁ. ADECE. Investimentos subsidiados. Fortaleza, 2010.

AMORA, Z. B. Aspectos históricos da industrialização do Ceará. In: SOUZA, S. (Coord.). História do Ceará. 2. ed. Fortaleza: Fundação Demócrito Rocha, 1994.
ARROYO, M. M. A globalização pensada a partir do espaço geográfico. In: MENDONÇA, F. A.; LOWEN-SAHR, C. L. ; SILVA, M. (Orgs.). Espaço e

tempo: complexidade e desafios do pensar e do fazer geográfico. Curitiba: Ademadan, 2009.

AYDALOT, P. Economie régionale et urbaine. Paris: Economica, 1985. 
. Dynamique spatiale et développement inégal. 2 . ed. Paris: Economica, 1980.

BOURGUINAT, H. Finance internationale. Paris: Presses Universitaires de France, 1992.

CAMAGNI, R. Economia urbana. Barcelona; Antoni Bosch, 2005.

CEARÁ. Diretrizes para o programa de governo - 2006/2010. Fortaleza: Seplan, 2006.

. Governo do Estado. Plano Plurianual 1992-1995. Fortaleza: 1991.

CHESNAIS, F. La prééminence de la finance au sein du "capital en général", le capital fictif et le mouvement contemporain de mondialisation du capital. In: BRUNHOFF, S. et al. La finance capitaliste. Paris: Actuel Marx/Presses Universitaires de France, 2006.

FISCHER, A. Zonas industriais e estratégias econômicas e espaciais. In: FIRKOWSKI, O. L. C.; SPOSITO, E. S. Indústria, ordenamento do território e transportes: a contribuição de André Fischer. São Paulo: Expressão Popular: UNESP. Programa de Pós-Graduação em Geografia, 2008.

. Industrie et espace géographique. Paris: Masson, 1994.

MANZAGOL, C. Lógica do espaço industrial. São Paulo: Difel, 1985.

MÉNDEZ, R.; CARAVACA, I. Organización industrial y territorio. Madrid: Síntesis, 1996.

MOUHOUD, E. M. Mondialisation et délocalisation des entreprises. Paris: Éditions La Découvert, 2008.
PEREIRA JÚNIOR, E. Industrialização e reestruturação do espaço metropolitano: reflexões sobre o caso de Horizonte-Pacajus (CE). Fortaleza: Eduece, 2005.

PETRELLA, R. Los limites a la competitividad: cómo se debe gestionar la aldea global. Buenos Aires: Universidad Nacional de Quilmes/Sudamericana, 1996.

RAFFESTIN, C. Por uma geografia do poder. São Paulo: Ática, 1993.

SANTOS, M. Espaço e método. 5. ed. São Paulo: Edusp, 2008.

Pensando o espaço do homem. 5. ed. São Paulo: Edusp, 2004.

A natureza do espaço. 3. ed. São Paulo: Hucitec, 1999.

SILVA, J. B. O algodão na organização do espaço. In: SOUZA, S. (Coord.). História do Ceará. 2. ed. Fortaleza: Fundação Demócrito Rocha, 1994.

SOUZA, M. S. Ceará: bases de fixação do povoamento e crescimento das cidades. In: SILVA, J. B.; CAVALCANTE, T. C.; DANTAS, E. W. C. (Orgs,). Ceará: um novo olhar geográfico. Fortaleza: Fundação Demócrito Rocha, 2005.

SPOSITO, E. S. Território, logística e mundialização. In: . (Org.). Dinâmica econômica, poder e novas territorialidades. Presidente Prudente: GAsPERR/Unesp, 1999. p. 99-113.

VELTZ, P. Le nouveau monde industriel. Édition revue et augmentée. Paris: Gallimard, 2008. 